УДК 330.131 .7

\title{
КЛАССИФИКАЦИЯ МАКРОЭКОНОМИЧЕСКИХ РИСКОВ ${ }^{1}$
}

\author{
(C) 2013 г. А. П. Панкратов
}

Южно-Российский государственный технический университет (НПИ)

В представленной статье автором рассмотрена дефинищия макроэкономического риска, его свойства и представлена классификация макроэкономических рисков.

Ключевые слова: макроэкономика; классификация; дефиниция; риск.

In the presented article author considers the definition of a macro-economic risk, its properties, and presents an actual classification of macroeconomic risks.

Key words: macroeconomics; classification; definition; the risk.

Развитие концепции рыночного хозяйствования происходит с учетом множества трудностей, которые являются специфическими для современного состояния отечественной экономики.

Введение принципа свободного взаимодействия хозяйствующих субъектов, обеспечение здоровой рыночной конкуренции неизбежно повышает неопределенность и риск. В этих условиях чрезвычайно остро стоит вопрос принятия оптимальных управленческих решений и предвидение их последствий. Большинство управленческих решений принимается в условиях риска.

Риск в экономике - это вероятность материальных потерь или неполучения дохода (прибыли) вследствие случайного изменения внешних и внутренних условий, сложившихся в национальной экономике, а также неоптимальных управленческих решений на микро- и макроуровне. С точки зрения национальной экономики можно выделить объективные и субъективные экономические риски.

Субъективный риск - это склонность (или способность) к риску, характеризующая индивидуальные особенности человека, управляющего политико-экономической единицей национальной экономики.

Объективные экономические риски связаны с неопределенностью внешней и внутренней экономической сред. В макроэкономике это - изменение конъюнктуры мирового рынка, мировые (региональные) финансовые кризисы, резкие колебания валютного курса и др. В рамках отдельной страны существуют национальные макроэкономические риски. Нередко они связаны со структурными сдвигами в производстве, бюджетным дефицитом, неуправляемой инфляцией. Результаты последствий макроэкономических рисков отдельной страны оказывают влияние на хозяйственную деятельность отдельных предприятий (фирм), усиливая их собственные микроэкономические риски.

Особая значимость макроэкономических рисков и фактическая не разработанность их характеристик в экономической литературе обусловили автора дать свое определение макроэкономическим рискам и классифицировать их по разновидностям.

Макроэкономические риски - это вероятность наступления ситуации в стране, связанная с принятием решения по преодолению неопределенности в социально-экономической системе страны, в процессе, которой имеется возможность количественно и качественно оценить вероятность достижения предполагаемых макроэкономических

1 Результаты работы получены при поддержке Минобрнауки РФ в рамках государственного задания на проведение НИОКР, шифр заявки 6.2989.2011 
показателей национальной экономики и отклонения от них.

Отклонения от необходимых показателей при этом возможны как отрицательного, так и положительного характера.

Среди свойств характерных для риска выделяют следующие:

- противоречивость, которая проявляется в том, что, с одной стороны, риск имеет важные последствия (ускоряет общественный технический прогресс, оказывает позитивное влияние на общественное мнение и духовную атмосферу общества), а с другой - ведет к авантюризму, волюнтаризму, субъективизму, тормозит социальный прогресс, порождает те или иные социально-экономические и моральные издержки;

- альтернативность предполагает необходимость выбора двух или нескольких возможных вариантов решений;

- неопределенность: риск является одним из способов снятия неопределенности, которая представляет собой незнание достоверного, отсутствие однозначности [4].

Риск возникает в случаях, когда вероятностный характер ситуации обусловлен действием некоторых опасностей и угроз, то есть некоторых объективных обстоятельств, по причине которых существует возможность неблагоприятного развития экономической ситуации. Действие разных типов опасностей и угроз приводит к возникновению различных по своей природе и происхождению рисков, поэтому для уточнения понимания категории «риск» необходимо классифицировать макроэкономические риски по ряду оснований.

Классификация рисков представляет собой сложную задачу, вследствие неоднозначности их идентификации по отношению к различным критериям классификации. Один и тот же риск можно отнести к разным видам [2].

Тем не менее, можно предложить некоторую укрупненную схему классификации макроэкономических рисков, представленную на рис. 1.

Деление рисков по сфере возникновения связано со средой их происхождения внутри страны: экономические, политические, социальные и прочие (природные риски, техногенного характера и др.).
По масштабам последствий риски могут быть поделены на высокие, средние и низкие. Такое деление рисков связано с определением масштаба последствий и относится к оценке уровня риска.

По формам выражения последствий риска условно можно разделить на материальные; финансовые; репутационные и моральные. Данная классификация относится к основным последствиям рискованной ситуации, поскольку экономические риски всегда имеют денежную форму выражения. Но в случае, например, лесных пожаров первичными будут потери имущества в натуральной форме, в случае распространения ложных сведений о стране (например, события военных действий, проходящих в Республике Южная Осетия в 2008 году: в результате действий западных СМИ в мировом сообществе действия Российской Федерации были «преподнесены» искажено, что сказалось репутации страны в первые дни военных действий) - репутационные.

По источнику возникновения макроэкономические риски могут быть разделены на внешнеэкономические риски, возникающие в связи с изменением ситуации во внешнеэкономической деятельности и внутриэкономические риски, связанные с изменением внутренней экономической среды.

Наименование основания классификации «по источнику возникновения» в определенной мере условно. Предлагается следующее деление, представленное на рис. 2. В соответствии с представленным рисунком дадим краткое описание указанных видов рисков.

Под внешнеэкономическими рисками следует понимать:

1) информационный риск - риск возникновения убытков из-за неправильной организации или умышленного нарушения информационных потоков на мировом уровне [1];

2) страновые риски - вероятность, что действия суверенного правительства или экономические, политические и социальные изменения в стране повлияют на способность должника, связанного с данной страной, исполнить свои обязательства:

- внешнеполитические - являются важнейшей составной частью страновых рисков. Суть их заключается в возможности 

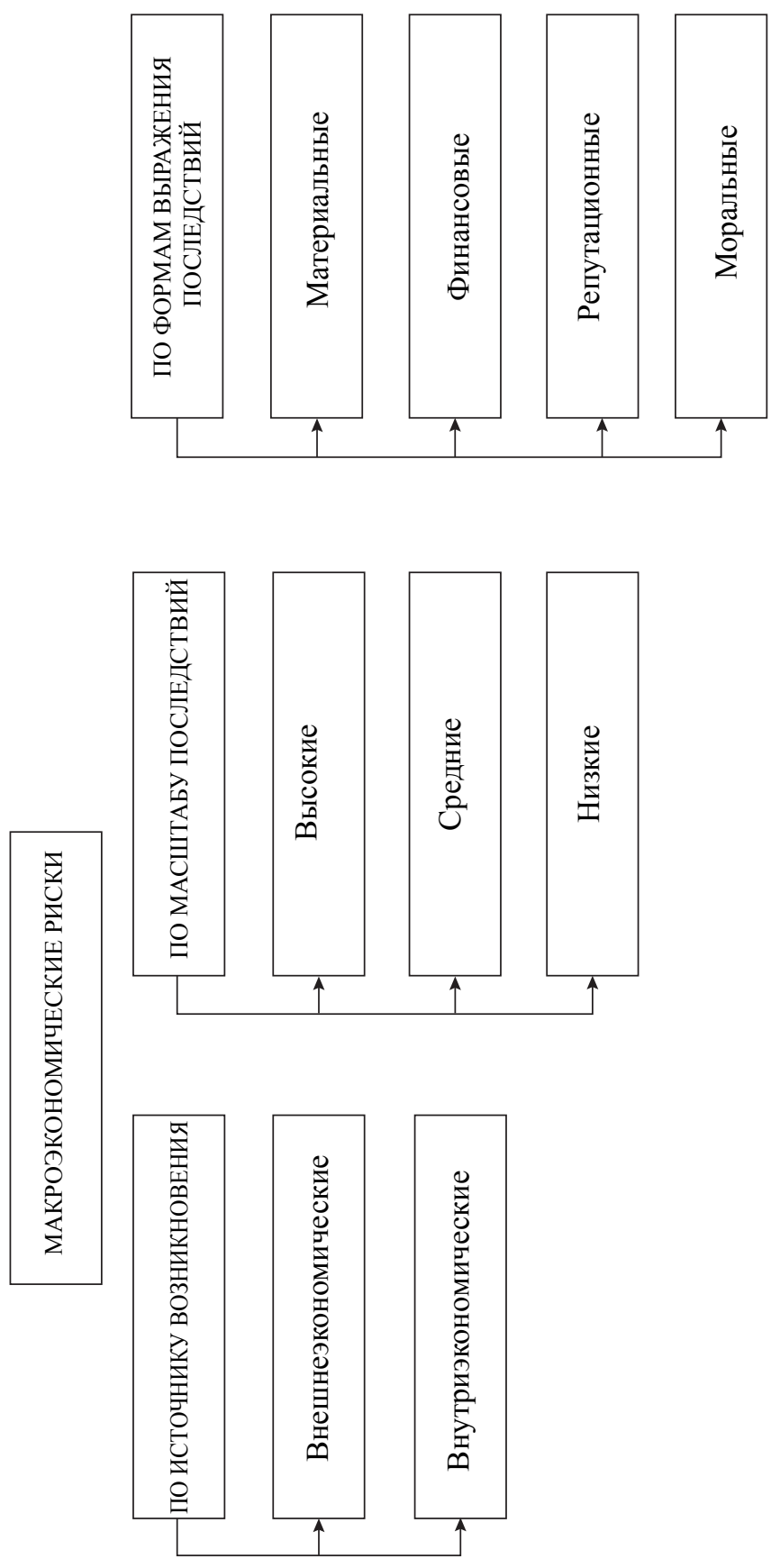

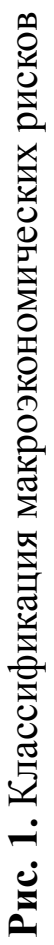

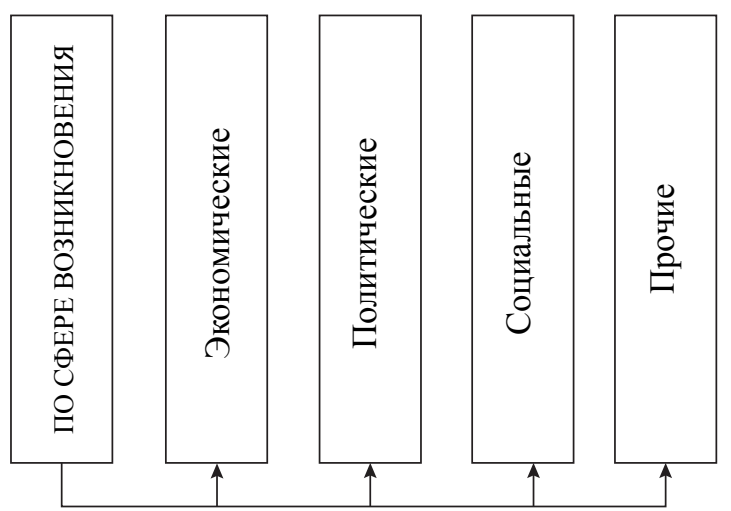




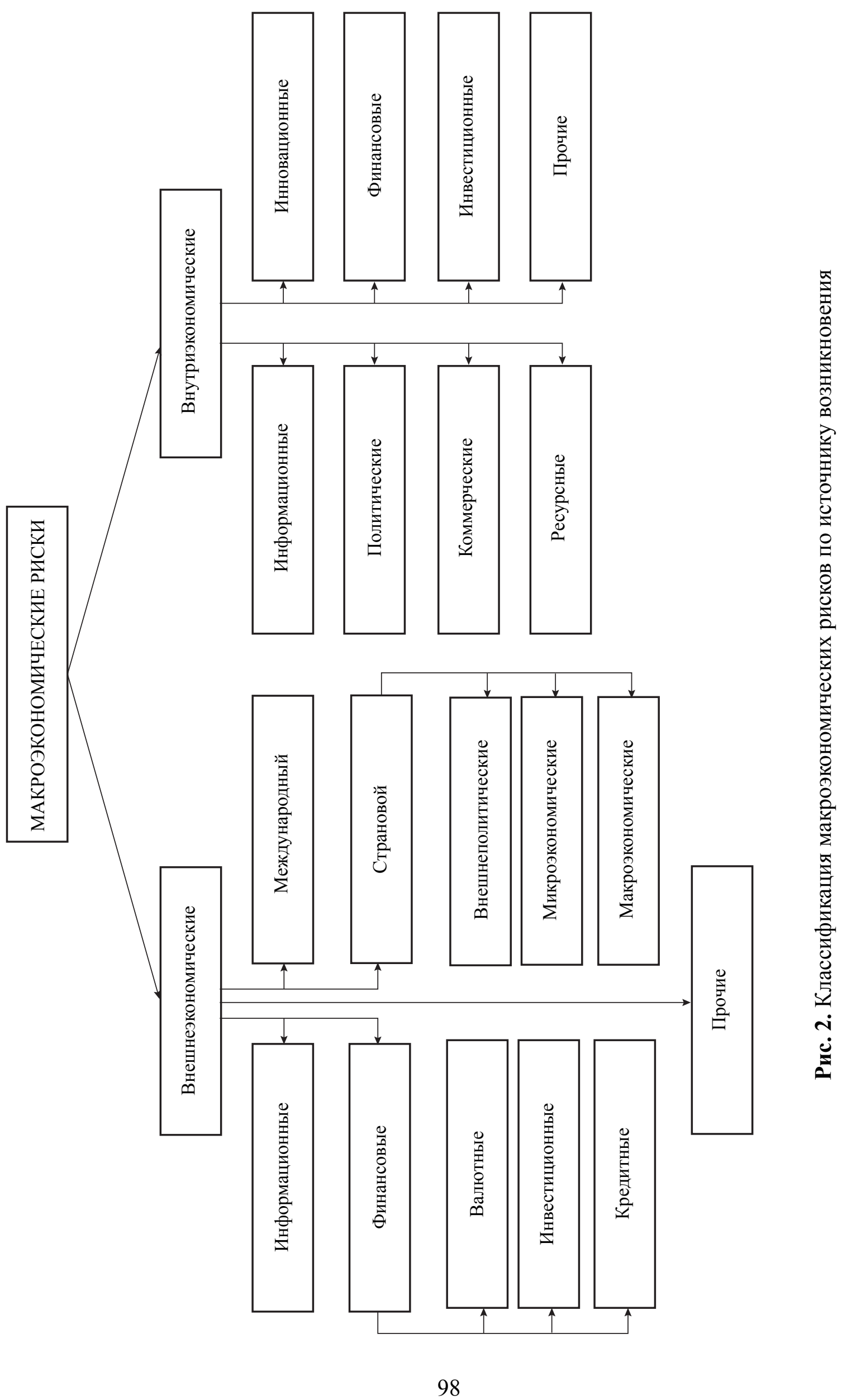


недополучения дохода или потери собственности иностранного предпринимателя или инвестора вследствие изменения социальнополитической ситуации в стране;

- микроэкономический - сюда относятся риски, специфичные для отрасли и отдельных предприятий;

- макроэкономический ассоциируется с вероятностью политических событий, отражающихся на всех иностранных субъектах в стране размещения;

3) международный риск - связанный с изменениями в конъюнктуре мирового рынка, с взаимоотношениями между странами, масштабными бедствиями и т. д.;

4) финансовые риски обусловлены вероятностью потерь финансовых ресурсов, т. е. денежных средств. Эти риски подразделяются на два вида: риски, связанные с покупательской способностью денег, и риски, связанные с вложением капитала. В рамках указанной выше классификации выделяют следующие финансовые риски:

- валютные риски представляют собой опасность валютных потерь, связанных с изменением курса одной иностранной валюты по отношению к другой, при проведении внешнеэкономических, кредитных и других валютных операций;

- кредитные риски - риски, связанные с возможным невозвратом суммы кредита и процентов по нему правительством страны;

- инвестиционные риски связаны с возможностью недополучения или потери прибыли в ходе реализации инвестиционных проектов на территории страны иностранными инвесторами;

5) прочие риски - такие как экологические, техногенные и другие риски мирового масштаба.

Представленное деление позволяет классифицировать только макроэкономические риски, то есть те риски, чьи последствия оказывают воздействие на различные уровни экономики и хозяйствующие субъекты. При рассмотрении видов рисков в классификации затрагивается их экономическая составляющая притом, что риски чаще всего по результату их проявления являются неэкономическими. Например, риски техногенного характера, которые используются в классификации только с позиции экономических последствий, которые они могут произвести на национальную экономику.

Внутриэкономические риски предлагается классифицировать следующим образом:

1) информационные - это риски связанные с финансовыми потерями из-за утраты, несанкционированного изменения информации из-за сбоев в функционировании информационных систем или их выхода из строя [1];

2) инновационные риски - это вероятность потерь, возникающих при вложении средств в производство товаров (услуг), которые, являются новыми с точки зрения технологии, научно-технических новшеств и которые возможно, не найдут ожидаемого спроса на рынке;

3) политические риски - риск имущественных (финансовых) потерь в связи с изменением политической системы, расстановкой политических сил в обществе, политической нестабильностью;

4) коммерческие риски представляют собой опасность потерь в процессе финансовохозяйственной деятельности предприятий определенной отрасли на территории страны;

5) финансовые риски - это риски, возникающие при осуществлении финансового предпринимательства или финансовых сделок;

6) инвестиционные риски - условия деятельности инвесторов с точки зрения возможности потери инвестиций и дохода от них;

7) ресурсные состоит в возможности появления потерь в результате отсутствия запаса прочности по ресурсам в случае изменения ситуации, в которой осуществляется хозяйственная деятельность;

8) прочие риски, риски которые могут возникнуть в результате деятельности различных институтов государственной власти, предприятий и гражданина страны в период своей хозяйственной деятельности и которые не указаны выше [5].

В условиях существующей российской политической системы, ориентированной на социальную рыночную экономику, механизм регулирования финансовых отношений макроуровня требует не меньшего внимания, чем микрорегуляторы экономических отношений. 
В каждой конкретной макроэкономической ситуации одновременно может действовать целый комплекс угроз и опасностей, порождающий определенные виды рисков. Классификация рисков может использоваться для целей их идентификации, что необходимо для оценки уровня как отдельных составляющих риска, так и его величины в целом. Без оценки уровня риска невозможно принять решение о действии в ситуации, связанной с риском, то есть управлять им [2].

Процесс управления риском предполагает, в первую очередь, количественный анализ, в результате которого находятся численные значения отдельных рисков, которые косвенно или прямо влияют на процесс управления. После оценки полученных значений рисков следует выработать национальную стратегию управления ими, в том числе и выработать соответствующие меры по уменьшению или даже полному предотвращению рисков. Но для создания эффективной системы управления рисками недостаточно ограничиваться выработкой подобной стратегии. Нужно создать также и механизм реализации выработанной стратегии, который, наряду с проведением ряда необходимых организа- ционных мероприятий, предусматривал бы также формирование специальных резервов для компенсации последствий возможных рисков.

\section{Литература}

1. Зинкевич В., Штатов Д. Информационные риски: анализ и количественная оценка [Электронный ресурс] / Франклин \& Грант: риск-консалтинг. - Режим доступа: http://www.franklin-grant.ru/ru/pr/pdf/bb_200702-01.pdf, свободный. - Загл. с экрана.

2. Кравцьов В. Б., Синявская Т. Г. Методы управления финансовыми рисками. Ростов н/Д: Рост. гос. эконом. ун-т (РИНХ), 2010.

3. Рогов В. А., Чудаков А. Д. Управление рисками. - Старый Оскол: ТНТ, 2011.

4. Тэпман Л. Н. Риски в экономике. / Под ред. проф. В. А. Швандара. - М.: ЮНИТИДАНА, 2002.

5. Шапкин A. C. Экономические и финансовые риски. Оценка, управление, портфель инвестиций. - М.: Издательско-торговая корпорация «Дашков и Ко», 2003.

24 января 2013 г. 


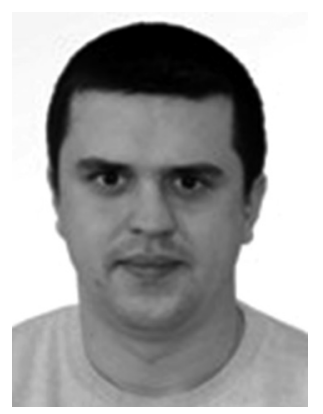

Алексей Павлович Панкратов - кандидат экономических наук, ассистент кафедры «Производственный и инновационный менеджмент» ЮРГТУ (НПИ). Автор исследований по проблемам экономических рисков, валютных рынков, применения экономико-математических методов в управлении.

Aleksey Pavlovich Pankratov - Ph.D., Candidate of Economics, assistant lecturer at the SRSTU (NPI) «Production Management and Management of the Enterprise» department. Author of numerous works in the field of the economic risks, currency exchange markets, using the economic and mathematical methodology for management.

346428 , г. Новочеркасск, ул. Просвещения, 132

132 Prosveshcheniya st., 346428, Novocherkassk, Rostov reg., Russia

Тел.: +7 (8635) 25-51-54; факс: +7 (8635) 25-56-66; e-mail: eiup@npi-tu.ru

\section{Стипендии 2013 года L'Oreal Россия - ЮНЕСКО для молодых российских ученых-женщин}

L'Oreal Россия при поддержке Комиссии Российской Федерации по делам ЮНЕСКО и Российской академии наук назначает 10 стипендий для молодых российских ученых-женщин с тем, чтобы содействовать научным карьерам российских женщин.

Эти стипендии размером в 400000 рублей каждая предназначены для ученых-женщин, кандидатов наук в возрасте до 35 лет, работающих в российских научных институтах и вузах по следующим дисциплинам: физика, химия, медицина и биология. Их цель заключается в том, чтобы позволить молодым женщинам-ученым стать известными, сделать заметной свою работу и ускорить осуществление своих проектов.

Представление кандидатур должно быть осуществлено с 1 февраля до 31 июля 2013 года. Формуляры для представления кандидатур доступны на сайте:

http://www.lorealfellowships-russia.org/ 